\title{
Time for harmonization: Pharmacists as immunizers across Canadian jurisdictions
}

\author{
Joseph Fonseca, BSc DiD; Jane Pearson Sharpe, BSc; Sherilyn K. D. Houle, BSP, PhD D; Nancy M. Waite, PharmD
}

\section{Background}

Improving vaccination coverage remains a global priority for reducing the health burden and social impact linked to at least 29 infectious diseases for which there are effective vaccines. ${ }^{1}$ While childhood vaccinations remain essential, an aging population means that the need for life-course vaccination programs that target adults is increasing. ${ }^{2}$ Pharmacists are particularly well suited to overcoming many of the challenges associated with vaccinating adult populations, hence the ongoing development of legislation for pharmacists as immunizers (PAIs) in Canada and abroad. ${ }^{1}$ This article provides an overview of the current Canadian landscape for pharmacists administering vaccines, highlights similarities and differences in legislation and regulation and discusses both challenges and opportunities for pharmacists who provide vaccination services.

PAIs in Canada have expanded since 2007, when BC became the first province to allow pharmacist-administered vaccinations. Since that time, Canada's decentralized pharmacy regulatory environment-where decision making takes place largely on a provincial/territorial $(\mathrm{P} / \mathrm{T})$ level-has resulted in $\mathrm{P} / \mathrm{T}$ differences in how quickly and to what extent PAI authority has been implemented. The result is a heterogenous PAI landscape across Canadian jurisdictions, with several interacting variables determining which, if any, vaccines a pharmacist can administer, to whom and under what funding model.

\section{Compiling and clarifying vaccination authority across Canadian jurisdictions}

A review of PAI authority across Canadian jurisdictions was undertaken prior to July 2019. Compiling and interpreting this authority was a challenge, due in part to the many factors influencing it, including regulatory scheduling of vaccines, pharmacist prescribing authority and $\mathrm{P} / \mathrm{T}$ routine vaccination programs. To ensure an accurate and up-to-date interpretation of each jurisdiction's PAI status, a cascading approach was used to review legislative and regulatory documents. $\mathrm{P} / \mathrm{T}$ health professions and/or pharmacy legislation were reviewed first. Information surrounding PAI authority came primarily from corresponding regulations of the $\mathrm{P} / \mathrm{T}$ colleges of pharmacy. In cases where the language of regulations was ambiguous-for example, some regulations cite $\mathrm{P} / \mathrm{T}$ "routine vaccine schedules" to describe PAIs-other resources such as $\mathrm{P} / \mathrm{T}$ pharmacy association communications and guidance documents were accessed. Finally, information in Table 1 was verified by experts in each jurisdiction in April 2019. It is important to note that some of the factors determining PAI authority are subject to frequent change and thus readers should consult the most recent information available through $\mathrm{P} / \mathrm{T}$ regulatory bodies. The discussion below illustrates some of the complexity involved with interpreting authority to vaccinate within and between jurisdictions.

Table 1 indicates PAI authority in each jurisdiction by individual vaccine, including pharmacists' authority to prescribe the vaccine, whether pharmacies can access publicly held vaccine supply and if government remuneration exists for its administration. Patient age requirements for pharmacistadministered vaccines are also specified.

\section{Similarities, differences and decision making}

To date, QC, NU and NT are the only Canadian jurisdictions that have yet to grant authority for pharmacists to vaccinate; the other 9 provinces and YT have introduced PAI legislation and regulations at different times since 2007. Most recently, YT passed a new Health Professions Act that replaces its old Pharmacy Act effective August 1, 2019, and includes authority for PAIs. ${ }^{3}$ As of June 2019, QC tabled provincial legislation

\footnotetext{
This series of articles has been accredited for 1.75 CEUs under CCCEP file \#: 8002-2019-2888-I-P. To earn your CEUs, please review each article, then click on www.pharmacists.ca/immunizers to complete a series of short assessments.
} 
TABLE 1 Pharmacists' vaccination authority across Canada

\begin{tabular}{|c|c|c|c|c|c|c|c|c|c|c|c|c|c|}
\hline & BC & $A B$ & SK & MB & ON & $Q C^{A, B}$ & NB & NS & PEI & NL & $\mathbf{Y T}^{\mathrm{A}, \mathrm{C}}$ & NWT $^{\mathrm{A}}$ & NU ${ }^{A}$ \\
\hline Influenza & $\sim *$ & $\nu^{* \$}$ & $\nu^{*} \$$ & $\sim^{*} \$$ & $\sim^{* \$}$ & $\mathbf{X}$ & $* \$$ & $\nu^{* \$}$ & $\nu^{* \$}$ & $\nu^{* \$}$ & $\mathbf{X}$ & $\mathbf{X}$ & $\mathbf{X}$ \\
\hline Pneumococcal & $* \$$ & $\sim^{* \$}$ & $\checkmark$ & $\sim^{* D}$ & $\checkmark$ & $\mathbf{X}$ & $\checkmark$ & $\checkmark$ & $\checkmark$ & $\checkmark$ & $\mathbf{x}$ & $\mathbf{X}$ & $\mathbf{X}$ \\
\hline Meningococcal & $* \$$ & $v$ & $\checkmark$ & $\checkmark$ & $\checkmark$ & $\mathbf{x}$ & $\checkmark$ & $\checkmark$ & $\checkmark$ & 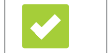 & $\mathbf{x}$ & $\mathbf{x}$ & $\mathbf{x}$ \\
\hline Hepatitis A & $\nu^{*}$ & $\nu$ & 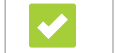 & $\checkmark$ & $\checkmark$ & $\mathbf{x}$ & $\checkmark$ & $\checkmark$ & $\checkmark$ & $\checkmark$ & $\mathbf{X}$ & $\mathbf{X}$ & $\mathbf{x}$ \\
\hline Hepatitis B & $v^{*}$ & $\checkmark$ & $\checkmark$ & $\checkmark$ & 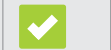 & $\mathbf{X}$ & $\checkmark$ & $\checkmark$ & $\checkmark$ & $\checkmark$ & $\mathbf{x}$ & $\mathbf{X}$ & $\mathbf{x}$ \\
\hline Varicella zoster (chickenpox) & $\nu^{*}$ & $\checkmark$ & $\checkmark$ & $\checkmark$ & $\checkmark$ & $\mathbf{x}$ & $\checkmark$ & $\checkmark$ & $\checkmark$ & $\checkmark$ & $\mathbf{x}$ & $\mathbf{x}$ & $\mathbf{X}$ \\
\hline Herpes zoster (shingles) & $\checkmark$ & 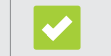 & $\checkmark$ & $\checkmark$ & $\checkmark$ & $\mathbf{x}$ & $\checkmark$ & $\checkmark$ & $\checkmark$ & $\checkmark$ & $\mathbf{x}$ & $\mathbf{X}$ & $\mathbf{x}$ \\
\hline Human papillomavirus & $* \$$ & $\checkmark$ & $\checkmark$ & $\$$ & $\checkmark$ & $\mathbf{X}$ & $\checkmark$ & $\checkmark$ & $\checkmark$ & 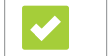 & $\mathbf{x}$ & $\mathbf{X}$ & $\mathbf{X}$ \\
\hline Polio & $\nu^{*}$ & $\checkmark$ & $v$ & $\checkmark$ & $\nu$ & $\mathbf{X}$ & $\checkmark$ & $\checkmark$ & $\checkmark$ & $\checkmark$ & $\mathbf{x}$ & $\mathbf{X}$ & $\mathbf{X}$ \\
\hline $\begin{array}{l}\text { Legislation allows pharmacist- } \\
\text { administration of: }\end{array}$ & $\begin{array}{l}\text { All } \\
\text { Schedule I, } \\
\text { IA \& II" }\end{array}$ & $\begin{array}{l}\text { All } \\
\text { Schedule } \\
\text { I \& || |12,13 }\end{array}$ & $\begin{array}{l}\text { All } \\
\text { Schedule } \\
\text { I \& }||^{4,35}\end{array}$ & $\begin{array}{l}\text { All } \\
\text { Schedule } \\
\text { I \& I|F,15,36 }\end{array}$ & $\begin{array}{l}\text { Specified } \\
\text { Schedule } \\
\text { I or I| } \mid \mathrm{G}, 37\end{array}$ & & $\begin{array}{l}\text { All } \\
\text { Schedule } \\
\text { I \& |||l,38 }\end{array}$ & $\begin{array}{l}\text { All } \\
\text { Schedule } \\
\text { I \& }|l| 17,39^{179}\end{array}$ & $\begin{array}{l}\text { All } \\
\text { Schedule } \\
\text { I \& } \|^{18}\end{array}$ & $\begin{array}{l}\text { All } \\
\text { Schedule } \\
\text { I \& || || }\end{array}$ & & & \\
\hline $\begin{array}{l}\text { Pharmacist authority to } \\
\text { prescribe vaccines: }\end{array}$ & No & Yes $^{H}$ & No & No & No & & Yes' & Yes $^{j}$ & Yes $^{\mathrm{K}}$ & No & & & \\
\hline
\end{tabular}

Pharmacists have authority to administer this vaccine.

"Pharmacists may access and administer publicly funded vaccine; note that for each infectious disease, the individual vaccine product(s) included in public programs through pharmacies may vary by jurisdiction. (Otherwise, patients requiring these vaccines can access the publicly funded supply through physicians or public health clinics at no charge or can pay the cost of privately acquired product through the pharmacy.)

${ }^{\text {\$ }}$ Remuneration is provided by provincial/territorial (P/T) government for vaccine administration at pharmacies. Patients may have the option to pay out-of-pocket for vaccines injection fees at pharmacies. ${ }^{A}$ Pharmacies in QC, YT, NT and NU can distribute vaccines through private purchase; patients can then transport the vaccine to a physician or other site approved for vaccine administration.

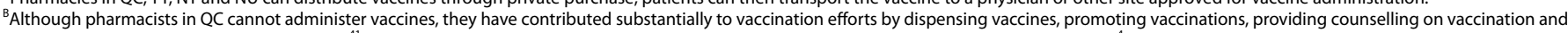
hosting nurses on-site to administer vaccines. ${ }^{41}$ Legislation tabled in June 2019 in QC would allow for pharmacists to administer vaccines, if passed. ${ }^{4}$

In May 2019, YT passed a new Health Professions Act that replaces its old Pharmacy Act effective August 1, 2019 and includes authority for pharmacists as immunizers (PAIs). ${ }^{3}$

DPneumococcal authority in MB only includes polysaccharide-containing vaccines.

EThis legislated authority may be subject to additional training or regulatory requirements specified outside P/T legislation.

F Both Schedule I and Schedule II require a prescription; 5 vaccines are excepted and can be administered, by a pharmacist, without a prescription, only if the patient is eligible for the publicly funded vaccine (human papillomavirus [HPV], Tdap, Td, PPV23 and influenza). ${ }^{15}$

${ }^{6}$ Only influenza can be administered without a prescription. ${ }^{37}$

HPharmacists with additional prescribing authority may prescribe vaccines. ${ }^{12}$

'Pharmacists can prescribe and administer all vaccines, except the 6 vaccines in provincial List B: Cholera (other than the oral, inactivated form which they can prescribe), European tick-borne encephalitis, Japanese encephalitis, rabies, typhoid and yellow fever. With additional training, pharmacists can administer but not prescribe the 6 vaccines in List B. ${ }^{16}$

'With additional training, pharmacists can prescribe vaccines for hepatitis A, hepatitis B, herpes zoster, varicella, HPV and typhoid, as well as administer vaccines for rabies, Japanese encephalitis and yellow fever. ${ }^{17}$

${ }^{k}$ With additional training, can prescribe vaccines for hepatitis A, hepatitis B, herpes zoster, HPV and vaccines for diphtheria, tetanus and acellular pertussis. ${ }^{18}$ 
that, if passed, will extend vaccination authority to pharmacists. ${ }^{4,5}$ Notably, all jurisdictions authorizing pharmacists to administer vaccines also include pharmacy students, which benefits student training and confidence, adds capacity to vaccine administration and education efforts and delivers positive patient experiences. ${ }^{6}$ The competency expectations for pharmacists trained to administer vaccines have been standardized by the National Association of Pharmacy Regulatory Authorities (NAPRA); therefore, training programs approved by each jurisdiction are similar and are usually accredited by the Canadian Council on Continuing Education in Pharmacy (CCCEP) $)^{7,8}$ None of the P/T specify roles for regulated pharmacy technicians in administering vaccinations, and at present, it is understood that these members of the P/T pharmacy colleges cannot administer vaccines. There is limited evidence surrounding the acceptability and feasibility of an enhanced pharmacy technician role administering vaccines, but some US states have begun to pursue legislation that would allow for this. At least 1 small trial in the United States has demonstrated relative success in training technicians to administer injections. ${ }^{9,10}$ It is uncertain whether support will grow for extending this controlled act to Canadian pharmacy technicians.

The majority of PAI legislation is dependent on NAPRA vaccine scheduling in some way. Eight of the 9 provinces with PAI legislation state that pharmacists can administer vaccines included in NAPRA's Schedule I and Schedule II. ${ }^{11-19}$ Ontario is an exception, where pharmacists can offer only a specific set of vaccines (unless a direct order or medical directive is in place for other vaccines), which happens to include some vaccines in both Schedule I and Schedule II. ${ }^{20}$ While scheduling by reference to NAPRA creates some similarities between provinces, navigating and interpreting jurisdictional policies is complicated by provincial deviations from NAPRA schedules and some ambiguity as to how vaccines are scheduled. That is, NAPRA describes Schedule I vaccines as those that are not "part of a routine immunization program in most/all provinces and territories" or that do not require "special enhanced public access due to disease outbreaks [such as] Meningococcus." ${ }^{21}$ Where provinces differ in their routine vaccination programs, or changes to routine programs are made, this description of NAPRA's Schedule I vaccines may cause confusion. Further still, some jurisdictions explicitly state that certain vaccines that would be considered Schedule II by NAPRA are Schedule I for that provincial regulation (e.g., in $\mathrm{AB}, 10$ of these vaccines are considered Schedule I). ${ }^{22}$ While important, NAPRA scheduling is only 1 component of interpreting PAI authority in a given Canadian jurisdiction.

Closely interacting with NAPRA scheduling is the question of prescribing authority for vaccines. For example, although $\mathrm{AB}$ states that some routine vaccines are considered Schedule $I$ and require a prescription in that province, those $A B$ pharmacists who have Additional Prescribing Authorization (APA) are able to prescribe Schedule I vaccines. ${ }^{12}$ Other jurisdictions, although more restrictive regarding pharmacist prescribing in general, have allowed pharmacists to prescribe and administer 1 subset of vaccines but only administer a different subset when a valid prescription is presented, such as in $\mathrm{NB},{ }^{16}$ $\mathrm{NS}^{17}$ and PE. ${ }^{18}$ Legislation defining pharmacists prescribing authority is also dynamic and future changes to these prescribing practices will likely continue to interact with pharmacists' provision of vaccination services.

Remuneration models and whether pharmacists can provide publicly funded vaccines present additional layers of complexity for PAIs. Pharmacists in all 9 provinces with PAI authority are able to administer and be remunerated for publicly funded influenza vaccine, although NL specifies that patients must be beneficiaries under the Newfoundland Prescription Drug Program in order for pharmacists to receive remuneration. ${ }^{23}$ Only $\mathrm{BC}, \mathrm{AB}$ and $\mathrm{MB}$ presently have public funding for pharmacist-administered vaccinations other than influenza. ${ }^{15,23-25}$ Interestingly, in MB, pharmacists can provide a subset of 5 publicly funded vaccines; however, if patients are eligible to receive any other vaccine through public funding, the pharmacist must refer them to another provider and cannot charge or administer, even at the patients' request. ${ }^{15}$ Unlike $\mathrm{MB}$, pharmacists in $\mathrm{ON}$ and SK, for example, are only required to notify the patients that they are eligible for a publicly funded vaccine through a different provider; these pharmacists can still administer and charge for such vaccines, if the patients choose. ${ }^{14,20}$ These types of policies encourage patient equity where additional public funding and remuneration are available for PAIs.

BC pharmacists' access to publicly funded vaccines is interesting in that some vaccines can be requested routinely, while access to other publicly funded vaccines depends on the context of the administration, not only which vaccine is being provided. ${ }^{26}$ For example, there are differences in pharmacist access to publicly funded vaccine supply depending on whether a BC pharmacist is providing vaccines: 1 ) as a supplement to school-based programs, 2) in postexposure situations, 3) during an outbreak or 4) as requested by a client under situations eligible in the British Columbia Centre for Disease Control (BCCDC) Immunization Manual. ${ }^{26}$ While recognizing that in certain circumstances, the pharmacist is the appropriate vaccine administrator, this scheme can be confusing to privately paying patients who may see others receiving the same vaccine without out-of-pocket expenses in some cases. As with other services, balancing person-centred care and sustainable public health programming in PAI regulation brings challenges.

\section{Challenges and opportunities for PAIs moving forward}

Since 2007, Canadian PAI practice has gained significant momentum, allowing pharmacists across the country to improve vaccine access and uptake. ${ }^{27,28}$ Despite its progress, PAI policy and authority clearly lacks standardization across 
jurisdictions. This heterogeneity can affect the public, pharmacists, other vaccination providers, public health units, regulators, advocacy groups, researchers and others in numerous ways:

1. Equity: Community pharmacy has been recognized as a venue with the accessibility and expertise required to increase public access to vaccines. ${ }^{28-31}$ Given the importance of vaccination, the inconsistencies that exist among jurisdictions surrounding PAIs and patients' eligibility for publicly funded vaccine products and/or injection fees are striking and unjustified. Recent independent reports indicate that Canadians believe health care services that are publicly funded when accessed through other providers should be similarly funded when accessed through a pharmacist. ${ }^{32}$ While additional public funding ostensibly benefits patient equity and access, economic analyses, such as those from a recent Ontario study, indicate that pharmacist-administered vaccines also have the potential to generate savings for the health care system. ${ }^{33}$ The heterogeneity in eligibility that exists for access to public funding through pharmacies can undermine tenets of patient equity, universality, portability and comprehensiveness of care. Thus, greater efforts are required to ensure patients have equitable service and comprehensible information regarding their eligibility for public funding.

2. Same training requirements, different implementation: All health care professional injection training programs must meet the same competencies as determined by the Public Health Agency of Canada and there is an additional competency (added by NAPRA) related to pharmacists being able to "safely and effectively administer (non-vaccine) substances by injection." ${ }^{4}$ So pharmacists are as "injection ready" as all other health care providers who vaccinate. They are also expected to provide comprehensive patient care, assessing and attending to a patient's medication needs whether for prevention or treatment. Yet, while other health care professionals can assess and administer any needed vaccines, pharmacists must navigate a convoluted regulatory pathway to determine whether and under what circumstances they can administer the vaccine, access publicly funded vaccines and/or charge the publicly funded health system for the service.

3. Identifying and interpreting authority to vaccinate: Navigation of PAI policies within each jurisdiction is challenging for pharmacists, other health care providers and patients alike. Professional associations and regulatory bodies have important roles in communicating the intent of new legislation and/or regulations and how these apply to different practice situations. The interconnected nature of NAPRA scheduling, pharmacist authority to prescribe and/or administer vaccines, funding sources and other factors not addressed in this article create a network of technical resources that can be difficult to interpret both in isolation and alongside one another. Inconsistent and asynchronous updates to these resources can further complicate their use. While practical and timely communications from regulatory and advocacy groups are beneficial, a more effective approach may be for regulators to consider pan-Canadian standards for pharmacists' authority to vaccinate. At a minimum, $\mathrm{P} / \mathrm{T}$ regulators should be cognizant of cross-jurisdictional implications such as pharmacy workforce mobility and how policy developments interact with other aspects of pharmacy scope of practice (e.g., prescriptive authority, administering injections to different age groups).

4. Knowledge mobilization across jurisdictions: Researchers examining the value of PAI services also face challenges in the current Canadian landscape. The variability that exists among jurisdictions typically generates results that are context specific, limiting knowledge mobilization and necessitating additional proof of concept for each jurisdiction and their respective policy makers. Reducing heterogeneity in jurisdictional authority, even to a small extent, may improve the generalizability of research findings and accelerate pharmacy's achievement of optimal scope nationwide.

\section{Limitations of this review}

The data compiled in this review reflect the dynamic nature of legislation and regulations, the availability of online information and the responsiveness of individuals contacted for additional information. Every attempt was made to incorporate legislative changes up to the time of manuscript completion. Notably, this review does not include the following:

- jurisdictional differences in pharmacist training requirements,

- the settings in which pharmacists or pharmacy students are permitted to administer vaccines (e.g., at long-term care facilities or workplace clinics) or

- the use of P/T medication review programs as an opportunity to assess individual vaccination status and/or needs.

\section{Conclusions}

While many Canadians now have access to pharmacists who can vaccinate, the inconsistencies that remain as a result of a decentralized pharmacy governance system (i.e., independent $\mathrm{P} / \mathrm{T}$ regulatory bodies) are prominent. Current discrepancies among Canadian jurisdictions include, but are not limited to, which vaccines pharmacists can administer, to whom and with what form of remuneration. These differences may create confusion for pharmacists, other vaccination providers and the public, and they have the potential to propagate inequities in health care delivery. Developing a strategic and uniform PAI scope of practice would be prudent for enhancing patient and 
provider equity, facilitating policy interpretation and permitting research-based knowledge mobilization. Ultimately, optimizing and standardizing pharmacists' scope as immunizers may empower the profession and contribute to reductions in vaccine-preventable disease and complications through increased patient access and uptake of vaccines.

From the School of Pharmacy, University of Waterloo, Kitchener, Ontario. Contact nmwaite@uwaterloo.ca.

ORCID iDs: Joseph Fonseca (ID https://orcid.org/0000-0002-3233-246X

Sherilyn K. D. Houle iD https://orcid.org/0000-0001-5084-4357

\section{References}

1. International Pharmaceutical Federation (FIP). An overview of current pharmacy impact on immunisation: a global report 2016. Available: https://www.fip .org/www/streamfile.php?filename=fip/publications/FIP_report_on_Immuni sation.pdf (accessed Jul. 17, 2019).

2. Teresa Aguado M, Barratt J, Beard JR, et al. Report on WHO meeting on immunization in older adults: Geneva, Switzerland, 22-23 March 2017. Vaccine 2018;36(7):921-31.

3. Government of Yukon. Health Professions Act-Pharmacists Regulation. Available: www.gov.yk.ca/legislation/regs/oic2019_097.pdf (accessed Jul. 13, 2019).

4. McCann MD. Bill 31- "An Act to Amend Mainly the Pharmacy Act to Facilitate Access to Certain Services." Quebec: National Assembly of Quebec; 2019.

5. Ordre des Pharmaciens du Quebec. Projet de loi 31 permettant la vaccination par les pharmaciens: une bonne nouvelle pour laccès. Available: https://www.opq.org/fr-CA/presse/communiques-de-presse/communiques2019/2019-06-13-projet-de-loi-31-permettant-la-vaccination-par-les-pharm aciens/ (accessed Jul. 12, 2019).

6. Church D, Johnson S, Raman-Wilms L, Schneider E, Waite N, Sharpe JP. A literature review of the impact of pharmacy students in immunization initiatives. Can Pharm J (Ott) 2016;149(3):153-65.

7. National Association of Pharmacy Regulatory Authorities. Supplemental competencies on injection for Canadian pharmacists. 2012. Available: https:// napra.ca/sites/default/files/2017-09/Supplemental_Competencies_on_Inject ion_for_Canadian_Pharmacists2012.pdf (accessed Mar. 20, 2019).

8. Canadian Council on Continuing Education in Pharmacy. Immunization and injection programs competency-mapped (programs currently accredited) as of Nov 8, 2018. 2018. Available: https://www.cccep.ca/ckfinder/userfiles/files/Immuni zation-Injection Programs 2018-11-8 Web-site (3).pdf (accessed Mar. 20, 2019). 9. Mckeirnan KC, Frazier KR, Nguyen M, Maclean LG. Training pharmacy technicians to administer immunizations. J Am Pharm Assoc 2018;58:174-8.e1. 10. Bertsch TG, Mckeirnan KC, Frazier K, Vanvoorhis L, Shin S, Le K. Supervising pharmacists' opinions about pharmacy technicians as immunizers. J Am Pharm Assoc 2019;59:527-32.

11. Government of British Columbia. Health Professions Act-Pharmacists Regulation. Available: http://www.bclaws.ca/EPLibraries/bclaws_new/docu ment/ID/freeside/417_2008 (accessed Dec. 18, 2018).

12. Government of Alberta. Pharmacy and Drug Act. Available: http://www .qp.alberta.ca/1266.cfm?page $=$ P13.cfm\&leg_type $=$ Acts\&isbncln $=9780779$ 801503 (accessed Dec. 18, 2018).

13. Government of Alberta. Health Professions Act: Pharmacists and Pharmacy Technicians Profession Regulation (Alberta Regulation 129/2006). Available: www.qp.alberta.ca/documents/Regs/2006_129.pdf (accessed Jan. 15, 2019).

14. Saskatchewan College of Pharmacy Professionals. Administration of drugs by injection supplementary guidelines for pharmacists. 2018. Available: https://scp.in1touch.org/document/3616/REF_Injections_Admin_Supp_ Gdlns_20180116.pdf (accessed Dec. 18, 2018).
15. Government of Manitoba. The Pharmaceutical Act-Pharmaceutical Regulation. Available: https://web2.gov.mb.ca/laws/regs/current/_pdf-regs .php?reg=185/2013 (accessed Dec. 18, 2018).

16. Government of New Brunswick. Regulations of the New Brunswick College of Pharmacists. Available: https://nbcp.in1touch.org/document/1733/2015 07 23 REGS bilingual.pdf (accessed Dec. 18, 2018).

17. Nova Scotia College of Pharmacists. Standards of practice-drug administration. 2017. Available: https://www.nspharmacists.ca/wp-content/ uploads/2017/10/SOP_DrugAdministration.pdf (accessed Dec. 18, 2018).

18. Government of Prince Edward Island. Regulated Health Professions ActPharmacists and Pharmacy Technicians Regulations. Available: https://www .princeedwardisland.ca/sites/default/files/legislation/r10-1-07-regulated_ health_professions_act_pharmacist_and_pharmacy_technician_regulat ions_0.pdf (accessed Jan. 15, 2019).

19. Newfoundland and Labrador Pharmacy Board. Newfoundland and Labrador Pharmacy Board Standards of Practice-Standards for the Safe and Effective Administration of Drug Therapy by Inhalation or Injection. 2015. Available: http://nlpb.ca/media/SOPP-Administration-of-Drug-Therapy-by-Inhalationor-Injection-June2015revisions.pdf (accessed Dec. 18, 2018).

20. Government of Ontario. Pharmacy Act, 1991, S.O. 1991, c. 36. Available: https://www.ontario.ca/laws/statute/91p36 (accessed Jan. 6, 2019).

21. National Association of Pharmacy Regulatory Authorities (NAPRA). Vaccines-Schedule I and NAPRA. Available: https://napra.ca/nds/vaccines (accessed Jan. 5, 2019).

22. Government of Alberta. Pharmacy and Drug Act-Scheduled Drugs Regulation (Alberta Regulation 66/2007). 2017. Available: www.qp.alberta.ca/1266 .$c f m$ ? page $=2007 \_066 . c f m \& l e g \_t y p e=$ Regs\&isbncln $=9780779795529$ (accessed Dec. 18, 2018).

23. Canadian Foundation for Pharmacy. 2017 Changing face of pharmacy. 2017. Available: https://cfpnet.ca/bank/document_en/118-2017-changingface-of-pharmacy.pdf (accessed Nov. 5, 2018).

24. Alberta College of Pharmacy. Pertussis vaccine to be provincially funded. 2018. Available: https://abpharmacy.ca/articles/pertussis-vaccine-be-provinc ially-funded (accessed Mar. 14, 2019).

25. Government of Alberta. Pneumococcal Polysaccharide 23-Valent Immunization Program. 2019. Available: https://open.alberta.ca/dataset/e52fe302-e9914b08-871d-f0994d72a9af/resource/0d8b01d2-b295-486f-b818-0890f8702c81/ download/aip-ps-pneumo-p-policy.pdf (accessed Mar. 9, 2019).

26. B.C. Ministry of Health-Pharmaceutical Services Division. Pharmacist access to publicly funded vaccines. 2018:1-2.

27. Buchan SA, Rosella LC, Finkelstein M, et al. Impact of pharmacist administration of influenza vaccines on uptake in Canada. CMAJ 2017;189(4): E146-52.

28. Isenor JE, Alia TA, Killen JL, et al. Impact of pharmacists as immunizers on influenza vaccination coverage in Nova Scotia, Canada. Hum Vaccines Immunother 2016;12(5):1225-8. 
29. Isenor JE, Edwards NT, Alia TA, et al. Impact of pharmacists as immunizers on vaccination rates: a systematic review and meta-analysis. Vaccine 2016;34(47):5708-23.

30. Alsabbagh MW, Church D, Wenger L, et al. Pharmacy patron perspectives of community pharmacist administered influenza vaccinations. Res Soc Adm Pharm 2019;15(2):202-6.

31. O’Reilly DJ, Blackhouse G, Burns S, et al. Economic analysis of pharmacist-administered influenza vaccines in Ontario, Canada. Clin Outcomes Res 2018;10:655-63.

32. Abacus Data conducted for Canadian Pharmacists Association. Pharmacists in Canada-a national survey of Canadians on their perceptions and attitudes towards pharmacists. March 2018. Available: www.pharmacists.ca/index. cfm/pharmacy-in-canada/pharmacists-in-canada/ (accessed Mar. 14, 2019).

33. Alsabbagh MW, Wenger L, Raman-Wilms L, et al. Pharmacists as immunizers, their pharmacies and immunization services: a survey of Ontario community pharmacists. Can Pharm J (Ott) 2018;151(4):263-73.

34. Saskatchewan College of Pharmacy Professionals. Administration of drugs by injection and other routes-guidelines for pharmacists. 2016. Available: http://saskpharm.ca/site/injection_main (accessed Dec. 18, 2018).

35. Saskatchewan College of Pharmacy Professionals. The regulatory bylaws of the Saskatchewan College of Pharmacy Professionals. 2018. Available:
https://scp.in1touch.org/document/3584/Bylaws_Regulatory_20161108.pdf (accessed Jan. 9, 2019).

36. Government of Manitoba. The Pharmaceutical Act. Available: https:// web2.gov.mb.ca/laws/statutes/ccsm/_pdf.php?cap=p60 (accessed Jul. 13, 2019).

37. Government of Ontario. Ontario Regulation 202/94: GENERAL under Pharmacy Act, 1991, S.O.,1991, c. 36. Available: https://www.ontario.ca/laws/ regulation/940202\#BK54 (accessed Jan. 6, 2019).

38. Government of New Brunswick. An act respecting the New Brunswick College of Pharmacists. Available: https://nbcp.in1 touch.org/document/1734/2014 Pharmacy Act.pdf (accessed Jul. 13, 2019).

39. Government of Nova Scotia. Pharmacist Extended Practice RegulationsPharmacy Act (Nova Scotia). Available: https://novascotia.ca/just/regulations/ regs/pharmextprac.htm (accessed Jul. 13, 2019).

40. Government of Newfoundland. Administration of drug therapy by inhalation or injection regulations under the Pharmacy Act, 2012. Available: https:// www.assembly.nl.ca/Legislation/sr/Regulations/rc140082.htm (accessed Jul. 13, 2019).

41. Sauvageau C, Dubé E, Bradet R, Mondor M, Lavoie F, Moisan J. Immunization services offered in Québec (Canada) pharmacies. Hum Vaccines Immunother 2013;9(9):1943-9. 